\title{
INVESTIGATION OF NONBUOYANT LAMINAR JET DIFFUSION FLAMES: A PARADIGM FOR SOOT PROCESSES IN TURBULENT FLAMES
}

\author{
C. Aalburg ${ }^{*}$, F.J. Diez ${ }^{*}$ and G.M. Faeth ${ }^{\dagger}$ \\ The University of Michigan \\ Ann Arbor, Michigan 48109 \\ P.B. Sunderland, ${ }^{\ddagger}$ D.L. Urban $^{* *}$ and Z.-G. Yuan ${ }^{* *}$ \\ NASA Glenn Research Center \\ Cleveland, Ohio 44135
}

\begin{abstract}
The structure and soot properties of steady nonbuoyant round laminar jet diffusion flames at microgravity were studied based on measurements obtained on orbit during three flights of the Space Shuttle Columbia (Flights STS-83, 94 and 107). The test conditions included ethylene- and propane-fueled flames burning in still air at ambient temperature of $300 \mathrm{~K}$ and ambient pressures of $35-130 \mathrm{kPa}$, for jet exit diameters of 0.40$2.70 \mathrm{~mm}$ and jet exit Reynolds numbers of 46-1186, to yield steady nonbuoyant round laminar jet diffusion flames with most of the flames near the laminar smokepoint. The first phase of the study involved evaluation of the classical analysis of the structure of steady nonbuoyant round laminar jet diffusion flames due to Spalding (1979), after empirically extending it to account for the presence of luminosity due to the presence of soot within the flames. It was found that the extended Spalding (1979) analysis provided excellent predictions of the flame shape properties of the test flames when radiative heat losses were small so that quenching and flame-tip opening were avoided. This analysis also shows that flame properties are identical functions of time for nonbuoyant laminar

${ }^{*}$ Research Fellow, Department of Aerospace Engineering.

${ }^{\dagger}$ A.B. Modine Professor, Department of Aerospace Engineering; Fellow, AIAA; Corresponding Author, Tel.: +1-734-764-7202, Fax: +1-734-936-0106, E.mail address: gmfaeth@umich.edu $\ddagger$ Staff Scientist, National Center for Microgravity Research.

**Chief, Microgravity Combustion Science Branch.
\end{abstract}

flames, even when jet exit velocities are varied; this implies that soot properties of these flames are universal functions of the extent of mixing of the flow, and that they should satisfy soot property state relationships. This behavior was subsequently confirmed by direct measurements of the soot properties of the test flames. Finally, the existence of soot property state relationships in nonbuoyant laminar jet diffusion flames has two important implications, as follows: (1) it helps explain the remarkable properties of turbulent diffusion flames (when effects of buoyancy are locally small) that soot yields ( $\mathrm{kg}$ soot $/ \mathrm{kg}$ of fuel burned) and soot structure properties are independent of location in the fuel-lean (overfire) region of the flames, and (2) it implies a potential for developing computationally tractable and robust methods for predicting soot properties within practical soot-containing turbulent flames (most of which are locally nonbuoyant), using the widely-accepted laminar flamelet concept that treats nonpremixed turbulent flames as a collection of laminar flamelets.

\section{$\underline{\text { Nomenclature }}$}

$\mathrm{C}_{\mathrm{f}}=$ empirical flame length parameter

$\mathrm{d}=$ jet exit diameter

$\mathrm{D}=$ mass diffusivity

$\mathrm{f}_{\mathrm{s}}=$ soot volume fraction

$\mathrm{L}_{\mathrm{o}}=$ distance between jet exit and virtual origin

$\mathrm{L}_{\mathrm{f}}=$ distance between jet exit and flame tip

$\dot{\mathrm{m}}=$ burner mass flow rate

$\mathrm{p}=$ pressure

$\operatorname{Re}=$ flame Reynolds number, $4 \dot{\mathrm{m}} /(\pi \mathrm{d} \mu)$

$\operatorname{Re}_{\mathrm{o}}=$ jet exit Reynolds number, $4 \dot{\mathrm{m}} /\left(\pi \mathrm{d} \mu_{\mathrm{o}}\right)$

$\mathrm{r}=$ radial distance

$\mathrm{Sc}=$ flame Schmidt number, $v / \mathrm{D}$

$\mathrm{SVF}=$ maximum soot volume fraction along a soot path 


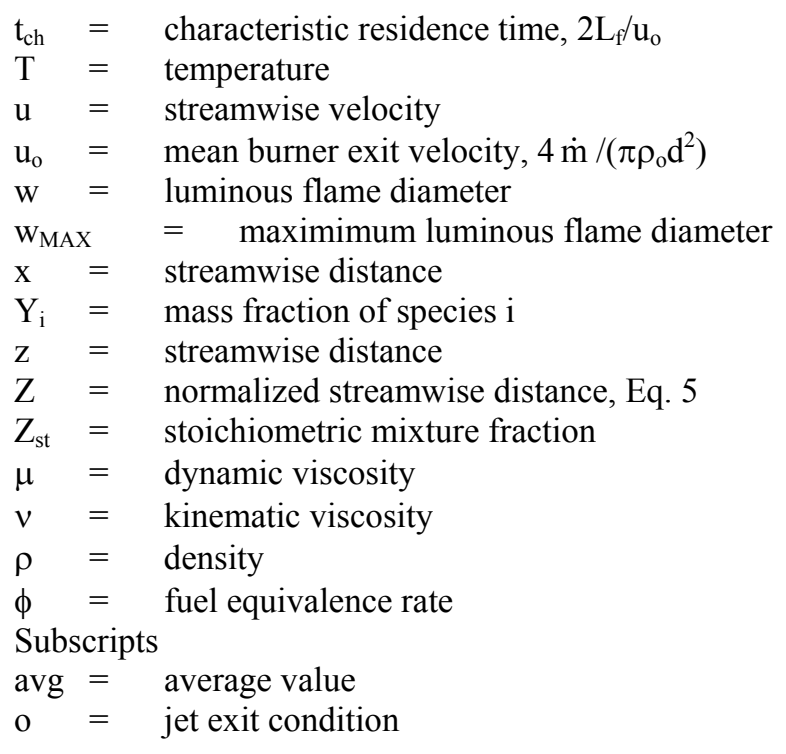

\section{INTRODUCTION}

A study of the structure and soot properties of steady nonbuoyant round laminar jet diffusion flames at microgravity is described, based on measurements obtained on orbit during three flights of the Space Shuttle Columbia (Flights STS-83, 94 and 107). The study was motivated by the fact that soot reaction properties in flames represents an important unsolved combustion property having significant relevance to society. For example, particulate soot emitted as a pollutant from combustion processes causes more deaths than any other combustion-generated pollutant, e.g., it is responsible for roughly 60,000 premature deaths each year in the U.S. alone. In addition, carbon monoxide emissions that result as a direct by-product of particulate soot emissions cause most deaths in unwanted fires, e.g., it is responsible for roughly 4,000 deaths each year in the U.S. alone. Furthermore, continuum radiation from particulate soot is mainly responsible for the growth and spread of unwanted fires, which involves roughly 5000 deaths each year in the U.S. alone. Finally, limited understanding of the complex processes that cause a solid material, particulate soot, to form in the high-temperature regions of flames that normally are associated with the combustion of solid flammable materials, represents a major impediment to the development of robust methods of computational combustion. Taken together, these observations amply motivate the study of soot processes in flames.

Soot processes in turbulent nonpremixed (diffusion) flames are of greatest practical interest, however, direct study of soot processes in turbulent flames is not feasible using either existing or anticipated technology. In particular, the unsteadiness and distortion of turbulent flames limits available residence times and spatial resolution within regions where soot reaction and radiative properties are most important. Thus, laminar diffusion flames generally are used as more tractable model flame systems to study processes relevant to of turbulent diffusion flames. It certainly can be argued that understanding soot processes in laminar flames is a necessary precursor to understanding them in turbulent flames. In addition, results for laminar flames can be directly relevant to turbulent diffusion flames, justified by the known similarities between the gas-phase properties of these two flame systems that has been responsible for the development of the widely-recognized laminar flamelet concept, where turbulent flames are treated as a collection of laminar flamelets. Unfortunately, buoyant laminar diffusion flames have not been found to have corresponding utility for studying processes of particulate matter in flames such as soot. Thus, a major objective of the present investigation was to study soot processes in nonbuoyant round laminar diffusion flames in an effort to determine the reasons why buoyant laminar diffusion flames yield problematical information about soot processes in practical turbulent diffusion flames and to determine whether study of nonbuoyant laminar diffusion flames provides a way of avoiding this difficulty.

Past research concerning soot properties in laminar diffusion flames is only discussed briefly in the following, see Haynes and Wagner, ${ }^{1}$ Glassman, ${ }^{2}$ Howard, ${ }^{3}$ Richter and Howard, ${ }^{4}$ Kennedy, ${ }^{5}$ and references cited therein, for more extensive reviews. Issues that are considered in the following include: soot structure and optical properties, soot reaction properties, laminar flame models, structure and radiation properties of turbulent diffusion flames, and radiation/soot interactions in laminar diffusion flames. The science objectives of the present investigation are then considered at the conclusion of the discussion of past research.

Interest in both the continuum radiation and optical properties of soot in flames, has motivated numerous studies of soot structure and optical properties, see Dalzell and Sarofim, ${ }^{6}$ Tien and Lee, ${ }^{7}$ Julien and Botet, ${ }^{8}$ Viskanta and Mengüc ${ }^{9}$ Koylu and coworkers, ${ }^{10-17}$ Krishnan et al., ${ }^{18,19}$ and references cited therein. A typical soot aggregate sampled from within one of the present steady nonbuoyant round laminar jet diffusion flames is illustrated in the Transmission Electron Microscope (TEM) photograph appearing in Fig. 1, however, samples of soot particulates obtained from flame environments generally are similar to this particle. Past research has shown that soot particles consist of nearly spherical and monodisperse primary 
soot particles (standard deviations of primary particle diameters in a given flame condition generally are less than $10 \%$ ) that are collected into branched aggregates having a wide range of numbers of primary particles per aggregate. Thus, soot particles are generally approximated to be polydisperse distributions of spherical primary particles that meet at a point, with the number of primary particles per aggregate generally represented by a log normal distribution function. Primary soot particle precursor particles have been observed having diameters of 3-10 nm but these particles are not observable using TEM and generally can only be observed using either UV light scattering and absorption or Scanning Mobility Particle Sizer (SMPS) techniques, see Zhou et al. ${ }^{20,21}$ and references cited therein. These precursor particles coalesce and undergo dehydrogenation to form the TEM observable nuclei of primary soot particles that generally have diameters of roughly $10 \mathrm{~nm}$. Subsequently, these particles increase in size by the primary particle surface growth mechanism and subsequently are oxidized by the primary particle surface oxidation mechanism, to yield primary particles having diameters in the range 10-60 nm. Detailed studies of the optical properties of soot aggregates have shown that they are mass fractal objects having a fractal dimension of roughly $1.8 ;^{12-17}$ as a result, their optical properties can be represented quite well by the Rayleigh-Debye-Gans scattering approximation for a polydisperse distribution of primary particles collected into mass fractal objects. In view of the significant uncertainties of concerning the refractive indices of primary soot particles, particularly involving effects of dehydrogenation, it generally is reasonable to approximate soot aggregates as independent primary particles, each satisfying the Rayleigh scattering approximation., ${ }^{7,9}$ Given these circumstances, soot optical properties are completely defined by the local soot volume fraction and refractive indices. Soot refractive indices are usually obtained from the classical measurements of Dalzell and Sarofim, ${ }^{6}$ however, these values have recently been confirmed in the visible by the measurements of Krishnan et al. ${ }^{18,19}$

Early studies of the reaction properties of soot in flame environments have been reviewed by Haynes and Wagner, ${ }^{1}$ Glassman, ${ }^{2}$ Howard, ${ }^{3}$ Richter and Howard, ${ }^{4}$ and Kennedy; ${ }^{5}$ therefore, the following discussion of soot reaction properties will be brief and will emphasize past studies in this laboratory. Studies of soot reaction properties in this laboratory include detailed measurements of flame structure and soot properties in 22 premixed and diffusion flames involving combustion of a variety of hydrocarbon fuels (methane, acetylene, ethylene, propylene, propane and benzene), gas temperatures of $1500-2350 \mathrm{~K}$ and pressures of $10-100 \mathrm{kPa}$, see Sunderland and coworkers $^{22-24}$ and $\mathrm{Xu}$ and coworkers. ${ }^{25-33}$ Measurements of primary soot particle surface growth in flames were found to be well represented by the Hydrogen-Abstraction/Carbon-Addition (HACA) mechanisms of soot surface growth of Colket and $\mathrm{Hall}^{34}$ and Frenklach and coworkers ${ }^{35-37}$ using empirical steric factors in these theories on the order of unity as expected. Measurements of primary soot particle surface oxidation in the flames were found to be well represented by reaction with $\mathrm{OH}$, as proposed by Neoh et al., ${ }^{38,39}$ with a parallel path involving direct surface attack by $\mathrm{O}_{2}$ using the classical rate expression due to Nagle and Strickland-Constable ${ }^{40}$ which was later confirmed by Park and Appleton. ${ }^{41}$ Finally, measurements of rates of nucleation of TEMobservable primary soot particles could be correlated by a simplified mechanism after assuming that these nucleation rates were controlled by the rate of development of large PAH molecules by the HACA mechanism. Taken together, these results imply that nucleation of TEM-observable primary soot particles and their subsequent surface growth is strongly dependent on the local concentrations of acetylene and $\mathrm{H}$, with relatively weak effects of temperature and pressure on these rates; similarly, primary particle surface oxidation is strongly dependent on local concentrations of $\mathrm{OH}$, with a relatively weak parallel path due to direct oxidation by $\mathrm{O}_{2}$, and weak effects of temperature and pressure of the dominant $\mathrm{OH}$ soot surface oxidation rate.

The structure of steady nonbuoyant laminar diffusion flames is a fundamental combustion problem that has attracted significant attention in the literature since the classical study of Burke and Schumann. ${ }^{42}$ This interest follows because this flame configuration provides a relatively simple configuration to gain a better understanding of the combined effects of convection, heat and mass transport and chemistry that control flame structure and flame response to varying flow conditions characteristic of practical turbulent flames. In addition, simple nonintrusive observations of flame shape can be used to evaluate predictions of flame structure. Similar to Burke and Schumann, ${ }^{42}$ most analyses of laminar diffusion flames have adopted the thin-flame sheet approximation as illustrated in Fig. 2 , where it is assumed that the fuel and oxidant molecules combine in stoichiometric proportions within an infinitely thin flame sheet. This implies that the fuel-rich interior portion of the flames contain fuel species and combustion products but not oxidizing substances whereas the fuel-lean exterior portion of the flames contain oxidizing species and combustion products but not fuel species. 
Several studies were undertaken in order to evaluate predictions of the structure of nonbuoyant laminar diffusion flames. The earliest studies of this type employed ground-based (drop tower and aircraft) microgravity facilities represented by the studies of Cochran and coworkers ${ }^{44-46}$ and Bahadori and coworkers. ${ }^{47,48}$ Two concerns arose about these measurements, however, as follows: (1) effects of different methods of igniting the flames suggested that transient development of the flames was incomplete for the limited periods of time available using groundbased microgravity facilities, and (2) the luminous shapes of these flames were largely due to the presence of glowing soot particles so that the relationship between these dimensions and the flame-sheet location (where the local mixture fraction is stoichiometric and is the flame sheet property predicted by the theories) must be known to properly interpret measurements and predictions of flame shapes. In particular, measurements of the structure and soot properties of buoyant round laminar jet diffusion flames burning in still air showed that ratios of soot-luminositylengths/flame-sheet lengths varied in the range 0.9-1.9 as flames made the transition from the soot-point condition (the first condition where soot is present in the flame) to the smoke-point condition (the first condition where the flame begins to limit soot). ${ }^{28-33}$ Subsequently, Sunderland et al. ${ }^{49}$ studied flame sheet locations in the presence of soot by photographing the flames through a $\mathrm{C}-\mathrm{H}$ line filter that uniquely imaged the flame sheet using a drop tower facility. These measurements were used to evaluate a simple flame sheet analysis due to Roper, ${ }^{50}$ however, this work was not able to evaluate either effects of flame unsteadiness on flame sheet behavior or effects of flame conditions on soot luminosity shapes. Finally, Urban et al. ${ }^{51}$ and Lin et al. ${ }^{52}$ measured the soot luminosity boundaries of steady nonbuoyant round laminar jet diffusion flames burning in still air, based on measurements carried out in the orbiting Space Shuttle Columbia (Flights STS-83 and 94). These results were compared with predictions based on the simplified flame structure analysis of Spalding ${ }^{53}$ described in more detail by Kuo et al. ${ }^{54}$ Unfortunately, most of the flight experiments involved flames having relatively large characteristic residence times which led to significant radiative heat losses, radiant quenching of the flame tips and tip-opening phenomena that cannot be treated by the simplified Spalding ${ }^{53}$ analysis where effects of radiative heat losses are ignored. This situation clearly places a high priority on obtaining flame sheet observations for steady nonbuoyant round laminar jet diffusion flames having short residence times and thus avoiding tipquenching and tip-opening effects. In particular, results of this nature would be extremely helpful for developing an understanding of the properties of soot- containing laminar flames of interest for practical turbulent flames.

The development of computationally tractable ways to simulate the structure of soot-containing flame environments also provides motivation for the present investigation. This methodology is described by Bilger $^{55}$ and Lockwood and Naguib, ${ }^{56}$ through implementation of the conserved scalar formalism of turbulent diffusion flames. This methodology is advanced by the observation of Bilger ${ }^{55}$ that gas phase scalar properties within laminar diffusion flames could be correlated solely as functions of the mixing level (usually represented by the local mixture fraction, which is the fraction of mass at a point that originated from the fuel stream, or the local fuel-equivalence ratio), even in the fuel-rich regions of flames that are affected by finite rate fuel decomposition and soot chemistry. He also proposed that these correlations from laminar flames, called state relationships, could be applied to turbulent flames, assuming that turbulent flames correspond to wrinkled laminar flames. This important idea, called the laminar flamelet concept of the conserved-scalar formalism, allows estimation of all scalar gas-phase properties in turbulent flames given a single conserved-scalar property such as the mixture fraction.

Use of the laminar flamelet concept vastly simplifies analysis of the scalar structure of turbulent diffusion flames. In addition, use of this approach has proven to be effective for predicting the structure and radiation properties of buoyant turbulent diffusion flames that either are soot-free or have small soot concentrations and thus negligible continuum radiation from soot, see Faeth and Samuelsen, ${ }^{58}$ Gore and coworkers, ${ }^{59-62}$ Kounalakis et al., ${ }^{63}$ Jeng et al. ${ }^{64,65}$ and Gore et al. ${ }^{66}$ A typical state relationship for scalar properties in soot-free flames is illustrated in Fig. 3, obtained from measurements of wet-carbon-monoxide laminar jet diffusion flames burning in air at atmospheric pressure. The main reason that scalar properties are only functions of the degree of mixing between the fuel and oxidant streams follows from the original observations of Burke and Schumann, ${ }^{42}$ as a result of the approximate equality of mass and heat diffusivities in flame environments as suggested by the simplified plot of scalar properties in a diffusion flame in Fig. 3. ${ }^{58}$ Another useful property of the laminar flamelet concept, evident from the measured state relationships, is that they can be directly measured in laminar jet diffusion flames so that these properties can be found readily for reactant systems where detailed chemical reaction and transport properties are not known or are so complex that the system is computationally intractable. 
Bilger $^{55}$ originally proposed the laminar flamelet concept for soot-containing diffusion flames, showing that scalar properties in these flames could be plotted as a function of mixture fraction (or equivalently the fuel-equivalence ratio) to obtain universal state relationships for scalar properties. An example of a plot of this nature appears in Fig. 4, obtained from measurements in laminar acetylene jet diffusion flames burning in air at various pressures. Also shown on this plot are equilibrium predictions of scalar properties for this flame system obtained by assuming local thermodynamic equilibrium for adiabatic combustion from the algorithm of Gordon and McBride. ${ }^{67}$ It is evident that the results are nearly universal for pressures in the range of 0.188-1.000 atm in spite of significant soot concentrations in this flame. This behavior is observed even though soot concentrations in flames vary by nearly an order of magnitude over the pressure range of these experiments, see Sunderland et $\mathrm{al}^{22}$ and Kim et al. ${ }^{31}$ The state relationships at the smallest pressure, $0.125 \mathrm{~atm}$, depart somewhat from the rest, however, mainly because the low-pressure flammability limit of this reactant system is being approached. Finally, the fuel-lean results are seen to approach equilibrium predictions, helping to explain why state relationships are observed in practical flame systems. At fuel-rich conditions, finiterate fuel decomposition and soot chemistry cause departures from equilibrium behavior but this departure is fortuitously universal, providing a way to estimate the scalar properties of soot-containing flames using simple experiments for systems where complex chemistry is not known very well and where complete chemical mechanisms will be computationally intractable for the foreseeable future.

Given promising results for the laminar flamelet concept when applied to species concentrations in sootcontaining laminar diffusion flames, attempts were made to apply this concept to the structure and radiation properties of soot-containing buoyant turbulent diffusion flames involving acetylene and ethylene burning in air at atmospheric pressure, see Gore and Faeth. ${ }^{68,69}$ As noted earlier, the properties of continuum radiation from soot in flames is largely controlled by the distribution of soot volume fractions; therefore, measurements in buoyant laminar flames were undertaken to determine whether state relationships were satisfied for this soot property in soot-containing diffusion flames. An example of these measurements for buoyant acetylene/air laminar jet diffusion flames at atmospheric pressure is illustrated in Fig. 5. Clearly, universal plots of soot volume fractions are not observed for these flames with similar behavior observed for other soot-containing laminar flames. ${ }^{68,69}$ Thus, crude approximations of soot volume fraction state relationships, used in conjunction with the conserved-scalar formalism to estimate the continuum radiation properties of buoyant turbulent diffusion flames, were relatively unsuccessful, see Gore and Faeth ${ }^{68,69}$

Local effects of buoyancy are small in most turbulent diffusion flames, even buoyant flames, because the velocities within these flames are relatively large. Unfortunately, because soot particles do not diffuse significantly due to their large size they are mainly convected by flow velocities in laminar diffusion flames which causes their behavior in laminar nonbuoyant and buoyant flames to be quite different; this effect is mainly responsible for the failure to find soot property state relationships in buoyant laminar flames as illustrated in Fig. 5. The reason for these differences is sketched in Fig. 6 which will be briefly discussed in the following, see Urban et al. ${ }^{51}$ for a more extensive discussion of this issue. The different soot paths through laminar buoyant and nonbuoyant flames occur because soot particles move along streamlines. Then, buoyancy causes the flow to accelerate in buoyant laminar flames which causes the ambient gas to be entrained by the flames. As a result, soot particles form near the flame sheet and then pass through the fuel-rich region of the flame for a time before passing back through the flame sheet near its tip. In contrast, nonbuoyant laminar flames decelerate with increasing distance from the flame sheet causing streamlines originating at the jet exit to diverge; as a result, soot particles form near the cool core of the flame and are drawn directly toward and through the flame sheet. In view of these observations, it is not surprising that state relationship properties for soot concentrations are different for buoyant and nonbuoyant laminar flames and that these properties are not universal for buoyant laminar flames. This still leaves unknown, however, whether nonbuoyant laminar jet diffusion flames exhibit universal state relationships for soot properties that are relevant to the soot properties of practical turbulent diffusion flames.

Several properties of turbulent diffusion flames have been reported that provide evidence that these flames might satisfy universal state relationships for soot properties. For example, it is widely recognized that typical soot-containing buoyant turbulent flames exhibit constant yields of combustion products per unit mass of fuel burned for a given fuel, independent of fire size, see the extensive tabulation of these yields reported by Tewarson. ${ }^{70}$ Such behavior suggests some sort of universality of the reaction properties of these flames which is not surprising because they do exhibit universal state relationships for scalar gaseous 
properties as noted in connection with Fig. 5. Other evidence suggests that this type of universality extends to soot properties in buoyant turbulent flames. First of all, buoyant turbulent diffusion flames in the long residence time regime (i.e., flames that are larger than roughly $1000 \mathrm{~mm}$ high), exhibit soot yields, kg soot per $\mathrm{kg}$ of fuel burned, for a given fuel, independent of fire size, see Koylu and Faeth. ${ }^{71}$ In addition, the soot emitted from these flames represents a single soot property (e.g., soot structure) population independent of where the soot is emitted from the flame, see Koylu and Faeth. ${ }^{71,72}$ Clearly, these are remarkable properties, suggesting that reactive universality of some type extends to reactions involving soot in these flames.

Examples of supporting the existence of soot property state relationships are illustrated in Fig. 7. This is a plot of the $\mathrm{CO}$ generation factor (the yield or $\mathrm{kg}$ of $\mathrm{CO}$ emitted from a flame per $\mathrm{kg}$ of fuel burned) plotted as a function of the soot generation factor (the yield or $\mathrm{kg}$ of soot emitted per $\mathrm{kg}$ of fuel burned) for a wide variety of fuels in buoyant turbulent diffusion flames in the long residence time regime. Clearly, all these flames exhibit surprising levels of universality of soot reaction properties that are supportive of behavior that should yield soot property state relationships. It is necessary, however, to measure these properties in properly nonbuoyant laminar diffusion flames where the interaction of effects of earth's gravity is eliminated.

Ground-based measurements of the properties of laminar jet diffusion flames clearly showed that truly soot-containing steady laminar diffusion flames could not be observed using ground-based microgravity facilities due to the limited times available at microgravity conditions and disturbances resulting from g-jitter, see Urban et al. ${ }^{37,73}$ Thus, to avoid these problems, experiments were carried out with nonbuoyant round laminar jet diffusion flames at longterm microgravity conditions on board the Space Shuttle Columbia (Flights STS-83 and 94). Unfortunately, most of the flames considered during these experiments had large characteristic residence times that resulted in significant radiant heat losses. For these flames, radiative heat losses tend to have the largest effect near the flame tip, where convective velocities and rates of reaction become small, resulting in a tip-opening phenomena that is not at all typical of laminar flamelets encountered in practical turbulent diffusion flames, see Urban et al. ${ }^{51,73}$ for more extensive discussions of the tip-opening phenomena of laminar diffusion flames at microgravity. Naturally, radiative heat losses and tip-opening phenomena are not typical of conditions considered during development of the simplified flame structure analysis of Spalding ${ }^{53}$ whereas tip opening with unburned fuel passing out of the flame along its axis clearly involves loss of universal state relationships representative of the laminar flamelet concept.

In summary, the conserved-scalar formalism in conjunction with the laminar flamelet concept that involves universal state relationships for scalar properties in turbulent flames offers a way to resolve problems of limited information about soot processes in flames and the computational intractability of detailed mechanisms of soot formation and oxidation in flames. Unfortunately, buoyant laminar diffusion flames do not have the same utility for finding state relationships for soot properties in diffusion flames and whether nonbuoyant laminar diffusion flames offer a proper way to measure soot-property finding state relationships is still not known at the present time. Finally, an attempt has been made to complete experiments to evaluate the potential existence of soot property state relations by observing soot-containing laminar jet diffusion flames at long-duration microgravity conditions on board the Space Shuttle Columbia (Flights STS-83 and 94); unfortunately, the flames observed during these experiments had large radiative heat losses and were subject to tip-opening phenomena that is not representative of typical laminar flamelet conditions in practical turbulent flames. In view of these observations, additional observations of soot-containing nonbuoyant laminar diffusion flames were undertaken at microgravity for nearly adiabatic conditions with the following specific objectives:

1. Measure soot and flame properties for various fuels, fuel flow rates, burner diameters and pressures in still environments.

2. Exploit the measurements to evaluate the simplified Spalding ${ }^{53}$ theory of flame structure in still environments.

3. Exploit both the simplified theory and the measurement to determine whether soot property state relationships exist within nonbuoyant and nearly adiabatic diffusion flames.

\section{EXPERIMENTAL METHODS}

\section{$\underline{\text { Test Apparatus }}$}

The flight-test apparatus was nearly identical to the arrangement used by Urban et al. ${ }^{51}$ and Lin et al. ${ }^{52}$ Laminar jet diffusion flames were stabilized at the exit of round fuel nozzles located along the axis of a 
windowed cylindrical chamber. The chamber had a diameter of $400 \mathrm{~mm}$ and a maximum length of 740 $\mathrm{mm}$. The fuels were burned in initially dry air within the chamber, however, the chamber was sufficiently large so that changes of the ambient conditions of the flames were relatively small. Various burner diameters were considered over the entire test series. The flames were ignited by a hot wire coil that was retracted from the nozzle exit once ignition was complete.

\section{$\underline{\text { Instrumentation }}$}

Soot luminosity boundaries and flame-sheet locations were measured from video images obtained using a color CCD video camera. Soot volume fraction distributions were obtained by deconvoluting laser extinction images for chord-like paths through the flames. The laser source was a diode laser yielding 1 $\mathrm{mW}$ of optical power at $634 \mathrm{~nm}$. The laser beam was expanded to a $40 \times 50 \mathrm{~mm}$ beam that passed through the flames and a laser line filter before being recorded by a CCD video camera. The extinction measurements were analyzed assuming Rayleigh scattering from primary soot particles with refractive indices from Dalzell and Sarofim. ${ }^{6}$

Soot temperature distributions were obtained by deconvoluting spectral radiation intensities for chordlike paths through the flames. The procedure involved considering the $650 / 830 \mathrm{~nm}$ line pair. The flame images were observed using two CCD cameras with appropriate line filters in the optical path. The measurements were analyzed assuming Rayleigh scattering from the soot particles similar to the extinction measurements.

\section{Test Conditions}

Test conditions from Space Shuttle Columbia Flights STS-83 and 94 are summarized in Lin et al.; ${ }^{52}$ test conditions from Space Shuttle Columbia Flight STS-107 are summarized in Aalburg et al. ${ }^{74}$ The general test ranges for soot properties are as follows: ethylene and propane as fuels; burner diameters of $0.40,0.801 .00$ and $2.70 \mathrm{~mm}$; pressures of $35-130 \mathrm{kPa}$; jet exit Reynolds numbers of 46-1183; characteristic residence times of 3-302 $\mathrm{ms}$; and luminous flame lengths of $15-110 \mathrm{~mm}$.

Flame shapes (the locus of the stoichiometric mixture fraction) were also evaluated, mainly based on the measurements of Sunderland et al. ${ }^{49}$ using drop tower microgravity facilities. The detailed test conditions for these measurements are summarized by Aalburg et al. $^{74}$ The test ranges for these measurements are as follows: methane, ethane and propane as fuels; burner diameters of $0.42,0.85,1.70$ and $3.25 \mathrm{~mm}$; pressures of $0.25-0.98$ atm; jet exit Reynolds numbers of 10-625; characteristic residence times of 3-429 ms; and flame-sheet lengths of 2-48 $\mathrm{mm}$.

\section{THEORETICAL METHODS}

Major assumptions of the Spalding ${ }^{53}$ analysis of the structure of laminar diffusion flames are as follows: (1) steady round laminar jet diffusion flames in a still environment, negligible effects of buoyancy, small Mach number flow, large flame aspect ratios so that the boundary layer approximations apply, reaction satisfies the thin flame-sheet approximation, equal diffusivities of all species and heat, constant transport properties, and adiabatic flames. See Lin et al. ${ }^{52}$ for justifications of these assumptions.

The soot-luminosity or flame-sheet length predicted by this analysis is:

$\left(\mathrm{L}_{\mathrm{f}}-\mathrm{L}_{\mathrm{o}}\right) / \mathrm{d}=3 \mathrm{C}_{\mathrm{f}} \operatorname{ReSc} /\left(32 \mathrm{Z}_{\mathrm{st}}\right)$

where $\mathrm{C}_{\mathrm{f}}$ is an empirical coefficient used to treat effects of soot luminosity. Equation (1) can be simplified to obtain the following form:

$\mathrm{L}_{\mathrm{f}}-\mathrm{L}_{\mathrm{o}}=3 \mathrm{C}_{\mathrm{f}} \dot{\mathrm{m}} \mathrm{Sc} /\left(8 \pi \mu \mathrm{Z}_{\mathrm{st}}\right)$

which implies that the flame length is proportional to the fuel flow rate but independent of the burner diameter. The maximum flame diameter is given by:

$\mathrm{w}_{\text {MAX }} \mathrm{Z}_{\mathrm{st}} / \mathrm{d}=9 / 16 @\left(\mathrm{z}-\mathrm{L}_{\mathrm{o}}\right) /\left(\mathrm{L}_{\mathrm{f}}-\mathrm{L}_{\mathrm{o}}\right)=9 / 16$

which implies that the maximum flame diameter is proportional to the burner diameter but is independent of the fuel mass flow rate. Finally, the flame shape is given by

$\mathrm{w} Z_{\mathrm{st}} / \mathrm{d}=1.73 \mathrm{Z}\left(\mathrm{Z}^{1 / 2}-1\right)^{1 / 2}$

where

$\mathrm{Z}=\left(\mathrm{z}-\mathrm{L}_{\mathrm{o}}\right) /\left(\mathrm{L}_{\mathrm{f}}-\mathrm{L}_{\mathrm{o}}\right)$

\section{RESULTS AND DISCUSSION}

\section{Flame Shapes}

Unlike earlier microgravity experiments, carried 
out during Space Shuttle Columbia Flights STS-83 and 94, the present flames all had small characteristic residence times, $2-52 \mathrm{~ms}$, so that radiant heat losses were small and the flames all had closed tips. The flames of Sunderland et $\mathrm{al}^{49}$ used to evaluate present flame-shape predictions were limited to flames having length/diameter ratios greater than three, so that the boundary layer approximations of the theory were satisfied; these flames also had small characteristic residence times, 3-15 ms, so that radiative heat losses were small and all the flames had closed tips.

Measurements and predictions of luminous flame lengths, plotted according to Eq. 2, are illustrated in Fig. 8. Luminous flame lengths are not affected very much by tip opening; therefore, results from Space Shuttle Columbia Flights STS-83, 94 and 107 are all shown on this plot. These flames generally approximate laminar smoke-point conditions. The experiments of Sunderland et $\mathrm{al}^{49}$ involved flame-sheet lengths observed through a filter even when soot is present. It is evident that the measurements fall into two groups that generally agree with Eq. 2: flame-sheet lengths with $\mathrm{C}_{\mathrm{f}}=0.56$ and soot-luminosity lengths (at the smoke-point condition) with $\mathrm{C}_{\mathrm{f}}=1.13$. Thus, the presence of soot at fuel-lean portions of the flame roughly doubles the visible flame length at a comparable fuel flow rate for laminar smoke-point conditions. A series of intermediate measurements from Flight STS-107, having half-darkened symbols, illustrates this behavior, making the transition between the flame-sheet (soot-free) limit and the laminar smoke-point limit with increasing flame lengths. Finally, flame lengths are proportional to the fuel flow rate, and double in length between soot- and smokepoint conditions but are little affected by other flame variables, as expected from Eq. 2.

Measurements and predictions of maximum flame diameters are illustrated in Fig. 9, plotted according to Eq. 3. In this case all the measurements of Sunderland et $\mathrm{al}^{49}$ are illustrated, although flames having $\left(\mathrm{L}_{\mathrm{f}}-\mathrm{L}_{\mathrm{o}}\right) / \mathrm{d}$ less than ten in this case all had flame aspect ratios smaller than three and are not considered elsewhere. Except for these small aspect ratio flames, the agreement between predictions and measurements in Fig. 9 is quite good. Notably, the soot content of the flames had little effect on maximum flame diameter, which is proportional to the burner diameter with little effect of other flame properties as expected from Eq. 3.

Finally, measured and predicted flame shapes for typical flames observed during Flight STS-107 are illustrated in Fig. 10. First of all, it is evident that Eqs. 4 and 5 provide excellent predictions of flame shapes for both soot-free and smoke-point conditions. In particular, the top two illustrations of Fig. 10 illustrate the effect of transitioning between soot- and smokepoint conditions, which causes the flame to increase in length by a factor of four (a factor of two due to doubling the fuel flow rate and another factor of two due to the presence of luminous soot particles at fuellean conditions). The bottom two illustrations in Fig. 10 show the effect of doubling the burner diameter, which roughly doubles the flame diameter even when flame lengths change. The effect of several other variables on flame shape are considered in Aalburg et al. $^{74}$ In general the agreement between measurements and the simplified Spalding ${ }^{53}$ analysis is remarkably good in view of the simplicity of the theory.

\section{Soot Property State Relationships}

Given the reasonably good evaluation of the predictions of the extended Spalding ${ }^{53}$ analysis of the structure of nonbuoyant round laminar jet diffusion flames, it is useful to consider the implications of this theory for other properties of these flames. One important result is illustrated in Fig. 11 which is a plot of the variation of fuel-equivalence ratios (which are single-valued functions of the mixture fraction) as a function of time for various soot paths extending from the burner exit through the flame sheet. The inset figure illustrates the two major types of streamlines (or soot pathlines) that must be considered for flames of this type that are separated by the dividing streamlines that bound the flow beginning at the burner exit from flows induced by entrainment of the jet flow: internal streamlines that originate at the burner exit and external streamlines that originate in the ambient environment. Remarkably, all the internal streamlines have identical variations of fuel-equivalence ratios as a function of time after leaving the burner exit. This behavior comes about because flows near the burner axis move at the largest velocities but must travel the largest distances to reach a given value of the equivalence ratio whereas flows near the dividing streamlines move at the smallest velocities but also travel the smallest distances to reach a given value of the fuel-equivalence ratio. Furthermore, this behavior is independent of the initial burner exit velocity because varying these velocities by a factor correspondingly varies distances traveled to reach a particular of fuel-equivalence ratio by the same factor, leaving the variation of fuel-equivalence ratio as a function of time unchanged. On the other hand, external streamlines exhibit a variety of behaviors of the variation of the of fuel-equivalence ratio as a function of time; fortunately, these streamlines involve fuel-lean conditions with correspondingly small soot concentrations that do not have a large impact on the soot properties of practical flames. Recalling from Fig. 
4, that nearly adiabatic soot-containing laminar diffusion flames exhibit state relationships for scalar properties, the observations of Fig. 11 imply that the reaction environments of soot passing along various internal streamlines, and having various initial velocities, should also be identical functions of time. Naturally, such behavior helps explain the universal behavior of various soot properties in turbulent diffusion flames described in connection with Fig. 7, after also invoking the widely-accepted laminar flamelet concept of turbulent flames.

Measurements of the soot properties of nearly adiabatic nonbuoyant laminar jet diffusion flames observed during the flight experiments offers a direct way to evaluate the potential existence of state relationships for soot properties at these conditions. An example of measurements along these lines is illustrated in Fig. 12. These results involve radial distributions of soot volume fractions at various distances from burner exit for an ethylene/air flame from a $1.6 \mathrm{~mm}$ diameter burner at $0.5 \mathrm{~atm}$ having a luminous flame length of $63 \mathrm{~mm}$. The two sets of soot volume fractions illustrated on the plot are obtained at $90 \mathrm{~s}$ and $130 \mathrm{~s}$ after ignition. The results in Fig. 12 indicate gradual widening of the luminous flame boundary and reduction of maximum soot concentrations with increased burning time; this comes about due to consumption of oxygen by the flame within the finite volume of the test chamber. A more interesting result is that most paths from the burner exit to the surroundings at each time exhibit nearly the same maximum soot concentration (in the range 1.5$2.0 \mathrm{ppm}$ ) which follows if the reaction environment is the same function of time for all interior streamlines as discussed in conjunction with Fig. 11. Thus, the observation of uniform maximum soot concentrations for internal streamlines from Fig. 12 satisfies a necessary conditions for the existence of soot property state relationships in nearly adiabatic nonbuoyant laminar jet diffusion flames. The path near the burner exit, $z=20 \mathrm{~mm}$, clearly yields a different result, which is expected for such conditions that involve soot properties along external streamlines.

The potential for state relationships for nearly adiabatic and nonbuoyant laminar jet diffusion flames is examined further with the results illustrated in Fig. 13. On this plot measurements of maximum soot volume function at each streamwise location, normalized by the average maximum soot volume fraction for all streamwise locations involving internal streamlines, $\mathrm{SVF} / \mathrm{SVF}_{\mathrm{avg}}$, is plotted as a function of distance from the burner exit normalized by the luminous flame length, $\mathrm{L} / \mathrm{L}_{\mathrm{f}}$. It is evident that $\mathrm{SVF}$ along internal streamlines have relatively uniform values, in agreement with the presence of soot property state relationships. Positions near the burner exit, however, involve smaller concentrations of soot than the rest because soot properties are dominated by behavior along external streamlines in this region.

The results illustrated in Figs. 11-13 are promising for the development of state relationships for the complex soot properties in flames. Analysis of available measurements from the flame experiments is continuing in order to further test this behavior, considering results from the large number of nearly adiabatic closed-tip flames available from Flight STS107.

\section{CONCLUSIONS}

Experimental observations of nonbuoyant round laminar jet diffusion flames at microgravity have yielded the following major conclusions:

1. The simplified analysis of Spalding, ${ }^{53}$ extended to allow for the presence of luminous soot particles beyond the flame sheet for flames at the smoke-point condition, yielded remarkably good predictions of luminous flame shapes (at the smoke point) and flamesheet shapes, with the empirical flame length parameter in the theory having values on the order of unity as expected.

2. Given a reasonably successful evaluation of the extended Spalding ${ }^{53}$ analysis for the structure of nonbuoyant laminar flames, this analysis suggests that state relationships for soot properties in nonbuoyant flames should be observed. In particular, the variation of mixture fractions as a function of time are identical for all soot paths through the flame, and all initial fuel velocities. Recalling that scalar properties in sootcontaining flames satisfy state relationships, this behavior implies that the reactive environment of soot particles along all paths through the flame are identical functions of time. Thus, soot properties in nonbuoyant laminar diffusion flames should exhibit universal soot properties as a function of mixture fraction as required for the presence of state relationships. These properties should also apply to turbulent diffusion flames through application of the laminar flamelet concept.

3. Present measurements of the structure of sootcontaining nonbuoyant laminar jet diffusion flames showed that maximum soot concentrations were identical for all paths from the burner exit through the flame sheet for closed-tip flames having small radiative heat losses. This is a necessary condition for the existence of soot property state relationships for 
nonbuoyant laminar diffusion flames and thus in turbulent diffusion flames as well through application of the laminar flamelet concept.

The next step in the development of this technology involves the use of experiments and numerical simulations to find soot property state relationships for some typical fuel and oxidant streams of practical diffusion flames. The availability of this information would constitute a significant advance toward developing a robust and computationally tractable way to estimate the properties of sootcontaining flames.

\section{ACKNOWLEDGEMENTS}

This research was sponsored by NASA Grant Nos. NCC3-661, NAG3-1878, NAG3-2048 and NAG3-2404 under the technical management of the NASA Glenn Research Center, Cleveland, Ohio. The authors would like to acknowledge the contributions of Ann P. Over and her associates at the NASA Glenn Research Center for development of the test apparatus and the crews of Space Shuttle Columbia Flights STS83, 94 and 107 who assembled the test apparatus and performed the experiments on orbit.

\section{REFERENCES}

${ }^{1}$ Haynes, B. S., and Wagner, H. G., "Soot Formation," Progress in Energy and Combustion Sciience, Vol. 7, No. 4, 1981, pp. 229-273.

${ }^{2}$ Glassman, I., "Soot Formation in Combustion Processes," Proceeding of the Combustion Institute, Vol. 22, 1988, pp. 295-311.

${ }^{3}$ Howard, J.B., "Carbon Addition and Oxidation Reactions in Heterogeneous Combustion and Soot Formation," Proceeding of the Combustion Institute, Vol. 23, 1990, pp. 1107-1127.

${ }^{4}$ Richter, H. and Howard, J.B., "Formation of Polycyclic Hydrocarbons and Their Growth to Soot," Progress in Energy and Combustion Sciience, Vol. 26, Nos. 4-6, 2000, pp. 562-611.

${ }^{5}$ Kennedy, I.M., "Models of Soot Formation and Oxidation," Progress in Energy and Combustion Sciience, Vol. 23, No. 2, 1997, pp. 95-132.

${ }^{6}$ Dalzell, W.H., and Sarofim, A.F., “Optical Constants of Soot and Their Application to Heat Flux Calculations," Journal of Heat Transfer, Vol. 91, No.
1, 1969, pp. 100-104.

${ }^{7}$ Tien, C. L., and Lee, S. C., "Flame Radiation," Progress in Energy and Combustion Science, Vol. 8, 1982, pp. 41-59.

${ }^{8}$ Jullien, R., and Botet, R., Aggregation and Fractal Aggregates, World Scientific, Singapore, 1987, Chapter 2.

${ }^{9}$ Viskanta, R., and Mengüc, M.P., "Radiation Heat Transfer in Combustion Systems," Progress in Energy and Combustion Science, Vol. 13, 1987, pp. 511-524.

${ }^{10}$ Köylü, Ü.Ö., and Faeth, G.M., "Structure of Overfire Soot in Buoyant Turbulent Diffusion Flames at Long Residence Times," Combustion and Flame, Vol. 89, No. 2, 1992, pp. 140-156.

${ }^{11}$ Köylü, Ü.Ö., and Faeth, G.M., "Radiative Properties of Flame-Generated Soot," Journal of Heat Transfer, Vol. 115, No. 2, 1993, pp. 408-417.

${ }^{12}$ Köylü, Ü.Ö., and Faeth, G.M., “Optical Properties of Overfire Soot in Buoyant Turbulent Diffusion Flames at Long Residence Times," Journal of Heat Transfer, Vol. 116, No. 1, 1994, pp. 152-159.

${ }^{13}$ Köylü, Ü.Ö., and Faeth, G.M., "Optical Properties of Soot in Buoyant Laminar Diffusion Flames," Journal of Heat Transfer, Vol. 116, 1994, pp. 971-979.

${ }^{14}$ Farias, T.L., Carvalho, M.G., Köylü, Ü.Ö., and Faeth, G.M., "Computational Evaluation of Approximate Rayleigh-Debye-Gans/Fractal-Aggregate Theory for the Absorption and Scattering Properties of Soot," Journal of Heat Transfer, Vol. 117, No. 1, 1995, pp. 152-159.

${ }^{15}$ Köylü, Ü.Ö., Faeth, G.M., Farias, T.L. and Carvalho, M.G., "Fractal and Projected Structure Properties of Soot Aggregates," Combustion and Flame, Vol. 100, No. 4, 1995, pp. 621-633.

${ }^{16}$ Faeth, G. M., and Köylü, Ü.Ö. "Soot Morphology and Optical Properties in Nonpremixed Turbulent Flame Environments," Combustion Science and Technology, Vol. 108, Nos. 4-6, 1995, pp. 207-229.

${ }^{17}$ Köylü, Ü.Ö., and Faeth, G.M., "Spectral Extinction Coefficients of Soot Aggregates from Turbulent Diffusion Flames," Journal of Heat Transfer, Vol. 118, No. 2, 1996, pp. 415-421.

${ }^{18}$ Krishnan, S.S., Lin, K.-C., and Faeth, G.M., "Optical Properties in the Visible of Overfire Soot in Large 
Buoyant Turbulent Diffusion Flames," Journal of Heat Transfer, Vol. 122, No. 3, 2000, pp. 517-524.

${ }^{19}$ Krishnan, S.S., Lin, K.-C., and Faeth, G.M., "Extinction and Scattering Properties of Soot Emitted from Large Buoyant Turbulent Diffusion Flames," Journal of Heat Transfer, Vol. 123, No. 2, 2001, pp. 331-339.

${ }^{20}$ Zhao, B.. Yang, Z., Wang, J., Johnston, M.V., and Wang, H., "Analysis of Soot Nanoparticles in a Laminar Premixed Ethylene Flame, by Scanning Mobility Particle Sizer," Aerosol Science and Technology, Vol. 37, 2003, pp. 611-620.

${ }^{21}$ Zhao, B.. Yang, Z., Johnston, M.V. Wang, H., Wexler, A.S., Balthasar, M., Kraft, M.,

"Measurement and Numerical Simulation of Soot Particle Size Distribution Functions in a Laminar Premixed Ethylene-Oxygen-Argon Flame,"Combustion and Flame, Vol. 133, No. 1/2, 2003, pp. 173-188.

${ }^{22}$ Sunderland, P.B., Köylü, Ü.Ö., and Faeth, G.M., "Soot Formation in Weakly Buoyant Acetylene-Fueled Laminar Jet Diffusion Flames Burning in Air," Combustion and Flame, Vol. 100, No. 1/2, 1995, pp. 310-322.

${ }^{23}$ Sunderland, P.B., and Faeth, G.M., "Soot Formation in Hydrocarbon/Air Laminar Jet Diffusion Flames," Combustion and Flame, Vol. 105, No. 1/2, 1996, pp. 132-146.

${ }^{24}$ Lin, K.-C., Sunderland, P.B., and Faeth, G.M., "Soot Nucleation and Growth in Acetylene/Air Laminar Coflowing Jet Diffusion Flames," Combustion and Flame, Vol. 104, No. 3, 1996, pp. 369-375.

${ }^{25} \mathrm{Xu}$, F., Sunderland, P.B., and Faeth, G.M., "Soot Formation in Laminar Premixed Ethylene/Air Flames at Atmospheric Pressure," Combustion and Flame, Vol. 108, No. 4, 1997, pp. 471-493.

${ }^{26}$ Xu, F., Lin, K.-C., and Faeth, G.M. "Soot Formation in Laminar Premixed Methane/Oxygen Flames at Atmospheric Pressure," Combustion and Flame, Vol. 115, No. 1/2, 1998, pp. 195-209.

${ }^{27} \mathrm{Xu}$, F., and Faeth, G.M., "Structure of the Soot Growth Region of Laminar Premixed Methane/Oxygen Flames," Combustion and Flame, Vol. 121, No. 4, 2000, pp. 640-650.

${ }^{28} \mathrm{Xu}, \mathrm{F}$., and Faeth, G.M., "Soot Formation in Laminar Acetylene/Air Diffusion Flames at Atmospheric Pressure," Combustion and Flame, Vol. 125, No. 1/2,
2001, pp. 804-819.

${ }^{29} \mathrm{Xu}$, F., El-Leathy, A.M., Kim, C.-H., and Faeth, G.M., "Soot Surface Oxidation in Hydrocarbon/Air Diffusion Flames at Atmospheric Pressure," Combustion and Flame, Vol. 132, No. 1, 2003, pp. 4357.

${ }^{30}$ El-Leathy, A.M., Xu, F., Kim, C.H., and Faeth, G.M., "Soot Surface Growth in Laminar Hydrocarbon/Air Diffusion Flames," AIAA Journal, Vol. 41, No. 5, 2003, pp. 856-865.

${ }^{31}$ Kim, C.H., El-Leathy, A.M., Xu, F., and Faeth, G.M., "Soot Surface Growth and Oxidation in Diffusion Flames at Pressures of 0.1-1.0 atm," Combustion and Flame, in press.

${ }^{32}$ El-Leathy, A.M., Kim., C.H,. Faeth, G.M. and Xu, F., "Soot Surface Reactions in HIgh-Temperature Laminar Diffusion Flames," AIAA Journal, in press.

${ }^{33}$ El-Leathy, A.M. Kim., C.H., and Faeth, G.M., "Primary Soot Particle Nucleation in Laminar Premixed and Nonpremixed Flames," Combustion and Flame, submitted.

${ }^{34}$ Colket, M.B., and Hall, R.J., "Successes and Uncertainties in Modelling Soot Formation in Laminar Premixed Flames," Soot Formation in Combustion, edited by H. Bockhorn, Springer-Verlag, Berlin, 1994, p. $442-470$.

${ }^{35}$ Frenklach, M., and Wang, H., "Detailed Modeling of Soot Particle Nucleation and Growth," Proceedings of the Combustion Institute, Vol. 23, 1990, pp. 15591566.

${ }^{36}$ Frenklach, M., and Wang, H., Soot Formation in Combustion, edited by H. Bockhorn, Springer-Verlag, Berlin, 1994, p. 165-192.

${ }^{37}$ Kazakov, A.,Wang, H., and Frenklach, M., "Detailed Modeling of Soot Formation in Laminar Premixed Ethylene Flames at a Pressure of 10 Bar," Combustion and Flame, Vol. 110, Nos. 1/2, 1995, pp. 111-120.

${ }^{38}$ Neoh, K.G., Howard, J.B., and Sarofim, A.F., "Soot Oxidation in Flames," Particulate Carbon, edited by D.C. Siegla and B.W. Smith, Plenum Press, New York, 1980, pp. 261-277.

${ }^{39}$ Neoh, K.G., Howard, J.B., and Sarofim, A.F., "Effect of Oxidation on the Physical Structure of Soot," Proceedings of the Combustion Institute, Vol. 20, 1984, pp. 951-957. 
${ }^{40}$ Nagle, J., and Strickland-Constable, R.F., "Oxidation of Carbon Between 1000-2000 ${ }^{\circ} \mathrm{C}$," Proceedings of the Fifth Carbon Conference, Vol. 1, 1962, pp. 154-164.

${ }^{41}$ Park, C., and Appleton, J.P., "Shock-Tube Measurements of Soot Oxidation Rates," Combustion and Flame, Vol. 20, No. 3, 1973, pp. 369-379.

${ }^{42}$ Burke, S. P., and Schumann, T.E.W., "Diffusion Flames," Industrial and Engineering Chemistry, Vol. 20, 1928, pp. 998-1004.

${ }^{43}$ Law, C.K., and Faeth, G.M., "Opportunities and Challenges of Combustion in Microgravity," Progress in Energy and Combustion Science, Vol. 20, No. 1, 1994, pp. 65-113.

${ }^{44}$ Haggard, J.B. Jr., and Cochran, T.H., "Stable Hydrocarbon Diffusion Flames in a Weightless Environment," Combustion Science and Technology, Vol. 5, 1972, pp. 291-298

${ }^{45}$ Edelman, R.B., Fortune, O.F., Weilerstein, G., Cochran, T.H., and Haggard, J.B., Jr., "An Analytical and Experimental Investigation of Gravity Effects upon Laminar Gas Jet-Diffusion Flames," Proceedings of the Combustion Institute, Vol. 14, 1972, pp. 399-412.

${ }^{46}$ Cochran, T.H., and Masica, W.J., "An Investigation of Gravity Effects on Laminar Gas Jet Diffusion Flames," Proceedings of the Combustion Institute, Vol. 13, 1970, pp. 821-829.

${ }^{47}$ Edelman, R.B., and Bahadori, M.Y., "Effects of Buoyancy on Gas-Jet Diffusion Flames: Experiment and Theory," Acta Astronautica, Vol. 13, No. 11/12, 1986, pp. 681-688.

${ }^{48}$ Bahadori, M.Y., Edelman, R.B., Stocker, D.P., and Olson, S.L., "Ignition and Behavior of Laminar Gas-Jet Diffusion Flames in Microgravity," AIAA Journal, Vol. 28, No. 2, 1990, pp. 236-244.

${ }^{49}$ Sunderland, P.B., Mendelson, B.J., Yuan, Z.-G., and Urban, D.L., "Shapes of Buoyant and Nonbuoyant Laminar Jet Diffusion Flames," Combustion and Flame, Vol. 116, No. 3, 1999, pp. 376-386.

${ }^{50}$ Roper, F.G., "Prediction of Laminar Jet Diffusion Flames; Part I. Theoretical Model," Combustion and Flame, Vol. 29, No. 3, 1977, pp. 219-226.
${ }^{51}$ Urban, D.L., Yuan, Z.-G., Sunderland, P.B., Linteris, G.T., Voss, J.E., Lin, K.-C., Dai, Z., Sun, K., and Faeth, G.M., "Structure and Soot Properties of Nonbuoyant Ethylene/Air Laminar Jet Diffusion Flames," AIAA Journal, Vol. 36, No. 8, 1998, pp. 13461360.

${ }^{52}$ Lin, K.-C., Faeth, G.M., Sunderland, P.B., Urban, D.L., and Yuan, Z.-G., "Shapes of Nonbuoyant Round Luminous Hydrocarbon/Air Laminar Jet Diffusion Flames." Combustion and Flame, Vol. 116, No. 3, 1998, pp. 415-431

${ }^{53}$ Spalding, D. B., Combustion and Mass Transfer, Pergamon, New York, 1979, pp. 185-195.

${ }^{54}$ Kuo, K.K., Principles of Combustion, Wiley, New York, 1986, pp. 360-370.

${ }^{55}$ Bilger, R.W., "Turbulent Jet Diffusion Flames," Progress in Energy and Combustion Science, Vol. 1, 1976, pp. 87-109.

${ }^{56}$ Lockwood, F.C., and Naguib, A.S., "The Predictions of the Fluctuations in the Properties of Free, Round-Jet, Turbulent Diffusion Flames," Combustion and Flame, Vol. 24, No. 1, 1975, pp. 109-124.

${ }^{57}$ Bilger, R.W., "Reaction Rates in Diffusion Flames," Combustion and Flame, Vol. 30, No. 3, 1977, pp. 277284.

${ }^{58}$ Faeth, G.M., and Samuelsen, G.S., "Fast-Reaction Nonpremixed Combustion," Progress in Energy and Combustion Science, Vol. 12, 1986, pp. 305-372.

${ }^{59}$ Gore, J.P., Jeng, S.-M., and Faeth, G.M., "Spectral and Total Radiation Properties of Turbulent Hydrogen/Air Diffusion Flames," Journal of Heat Transfer, Vol. 109, No. 1, 1987, pp. 165-171.

${ }^{60}$ Kounalakis, M.E., Gore, J.P., and Faeth, G.M., "Turbulence/Radiation Interactions in Nonpremixed Hydrogen/Air Flames," Proceedings of the Combustion Institute, Vol. 22, 1988, pp. 1281-1290.

${ }^{61}$ Gore, J.P., Jeng, S.-M., and Faeth, G.M., "Spectral and Total Radiation Properties of Turbulent Carbon Monoxide/Air Diffusion Flames," AIAA Journal, Vol. 25, No. 2, 1987, pp. 339-345.

${ }^{62}$ Kounalakis, M.E., Gore, J.P., and Faeth, G.M., "Mean and Fluctuating Radiation Properties of Turbulent Nonpremixed Carbon Monoxide/Air 
Flames," Journal of Heat Transfer, Vol. 111, No. 4, 1989, pp. 1021-1030.

${ }^{63}$ Kounalakis, M.E., Sivathanu, Y.R., and Faeth, G.M., "Infrared Radiation Statistics of Nonluminous Turbulent Diffusion Flames," Journal of Heat Transfer, Vol. 113, No. 2, 1991, pp. 437-445.

${ }^{64}$ Jeng, S.-M., Lai, M.-C., and Faeth, G. M., "Nonluminous Radiation in Turbulent Buoyant Axisymmetric Flames," Combustion Science and Technology, Vol. 40, No. 1-4, 1984, pp. 41-53.

${ }^{65}$ Jeng, S.-M., and Faeth, G.M., "Radiative Heat Fluxes Near Turbulent Buoyant Methane Diffusion Flames," Journal of Heat Transfer, Vol. 106, No. 4, 1984, pp. 886-888.

${ }^{66}$ Gore, J.P., Faeth, G.M., Evans, D., and Pfenning, D.B., "Structure and Radiation Properties of LargeScale Natural Gas/Air Diffusion Flames," Fire and Materials, Vol. 10, 1986, pp. 161-169.

${ }^{67}$ Gore, J.P., and Faeth, G.M., "Structure and Spectral Radiation Properties of Turbulent Ethylene/Air Diffusion Flames," Proceedings of the Combustion Institute, Vol. 21, 1986, pp. 1521-1531.

${ }^{68}$ Gore, J.P., and Faeth, G.M., "Structure and Radiation Properties of Luminous Turbulent Acetylene/Air Diffusion Flames," Journal of Heat Transfer, Vol. 110, No. 1, 1988, pp. 173-181.

${ }^{69}$ Sivathanu, Y.R., and Faeth, G.M., "Generalized State Relationships for Scalar Properties in Nonpremixed Hydrocarbon/Air Flames," Combustion and Flame, Vol. 82, No. 2, 1990, pp. 211-230.

${ }^{70}$ Tewarson, A., "Generation of Heat and Chemical Compounds in Fires," in SFPE Handbook of Fire Protection Engineering, National Fire Protection Association, Quincy, MA, 1988, pp. 1-179 to 1-199.

${ }^{71}$ Köylü, Ü.Ö., Sivathanu, Y., and Faeth, G.M., "Carbon Monoxide and Soot Emissions from Buoyant Turbulent Diffusion Flames," Proceedings of the Third International Symposium on Fire Safety Science, Elsevier, London, 1991, pp. 625-634.

${ }^{72}$ Köylü, Ü.Ö., and Faeth, G.M., “Carbon Monoxide and Soot Emissions from Liquid-Fueled Buoyant Turbulent Diffusion Flames," Combustion and Flame, Vol. 87, No. 1, 1991, pp. 61-76.

${ }^{73}$ Urban, D.L., Yuan, Z.-G., Sunderland, P.B., Lin, K.C., Dai, Z., and Faeth, G.M., "Smoke-Point Properties of Nonbuoyant Round Laminar Jet Diffusion Flames, ” Proceedings of the Combustion Institute, Vol. 28, 2000, pp. 1965-1972.

${ }^{74}$ Aalburg, C., Diez, F.J., Faeth, G.M., Sunderland, P.B., Urban, D.L. and Yuan, Z.-G., "Shapes of Nonbuoyant Round Hydrocarbon-Fueled Laminar Jet Diffusion Flames in Still Air," Combustion and Flame, submitted. 


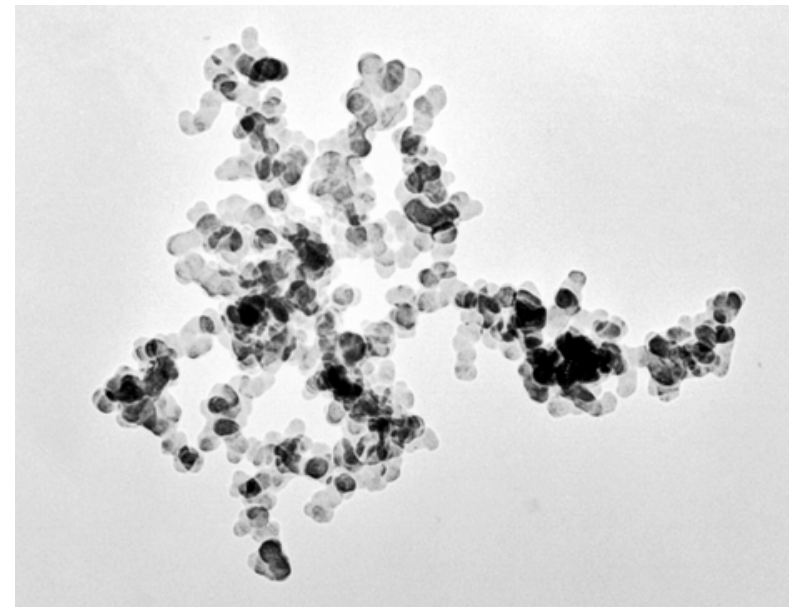

Fig. 1 TEM photograph of a typical soot aggregate obtained in the soot layer of an ethylene-air flame at $100 \mathrm{kPa}$. The maximum dimension of the aggregate is $1100 \mathrm{~nm}$.

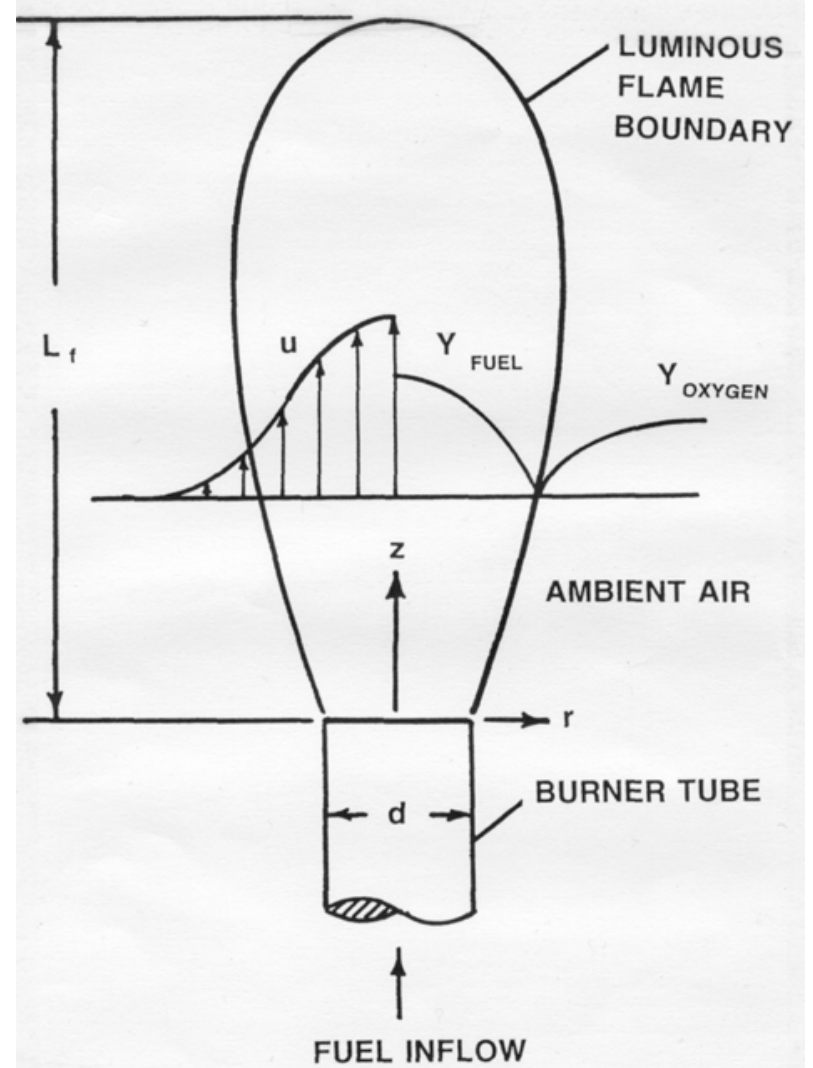

Fig. 2 Sketch of the structure of a laminar jet diffusion flame in a still air environment according to the Burke and Schumann ${ }^{43}$ thin diffusion flame sheet approximation.

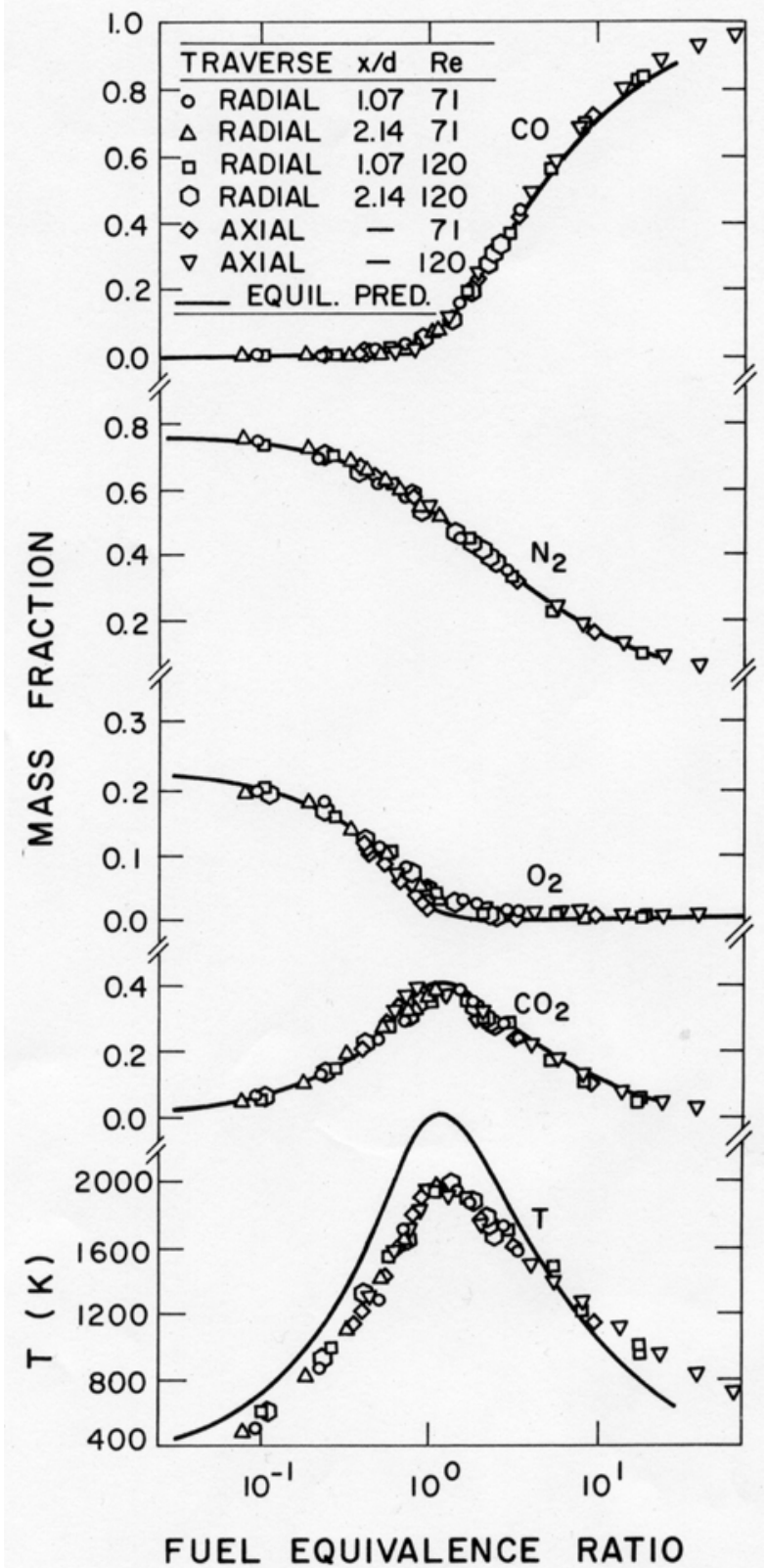

Fig. 3 State relationships for scalar properties for sootfree carbon monoxide laminar jet diffusion flames burning in still air at atmospheric pressure. From Faeth and Samuelsen. ${ }^{58}$ 


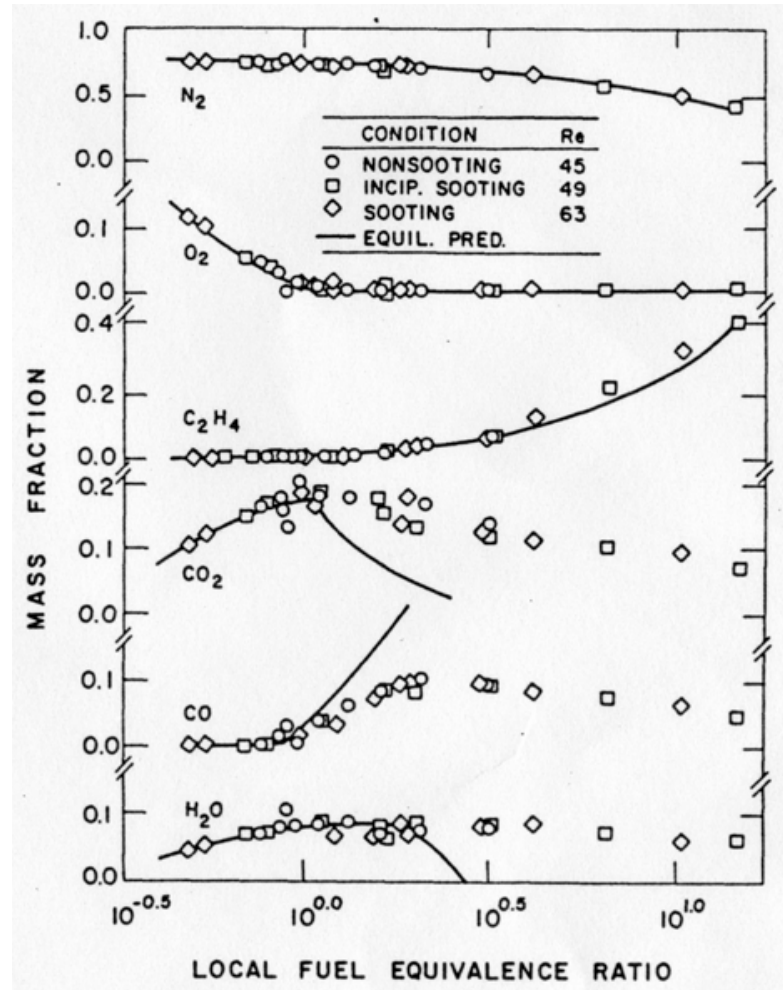

Fig. 4 State relationships for scalar properties for sootcontaining acetylene laminar jet diffusion flames burning in still air at pressures of 0.125-1.000 atm.

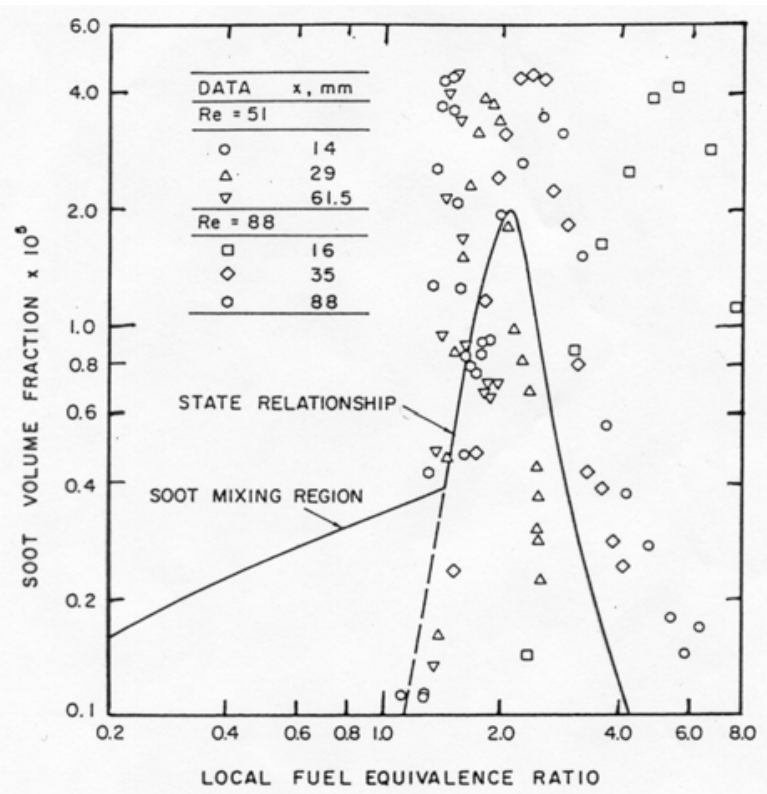

Fig. 5 State relationships for soot volume fraction distributions in soot-containing acetylene laminar jet diffusion flames burning in still air at atmospheric pressure. From Gore and Faeth. ${ }^{67}$

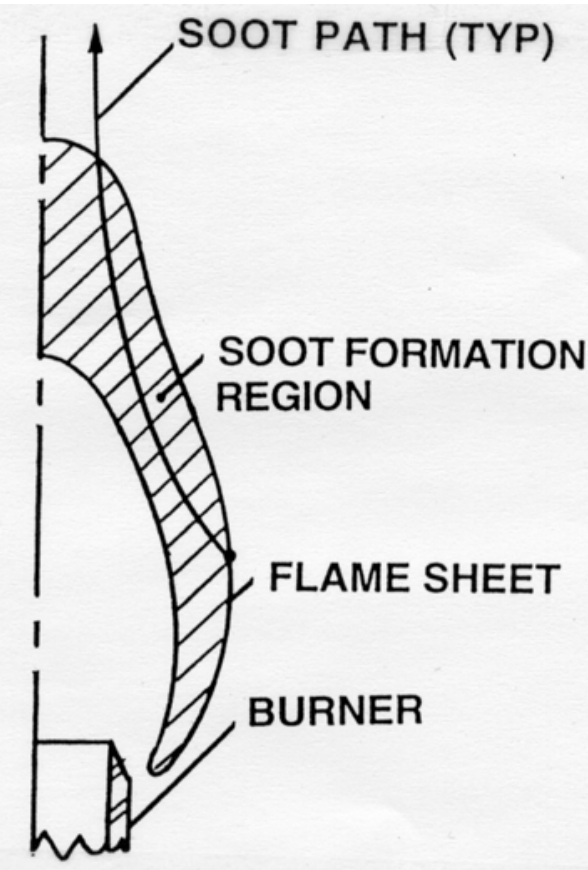

BUOYANT FLAME

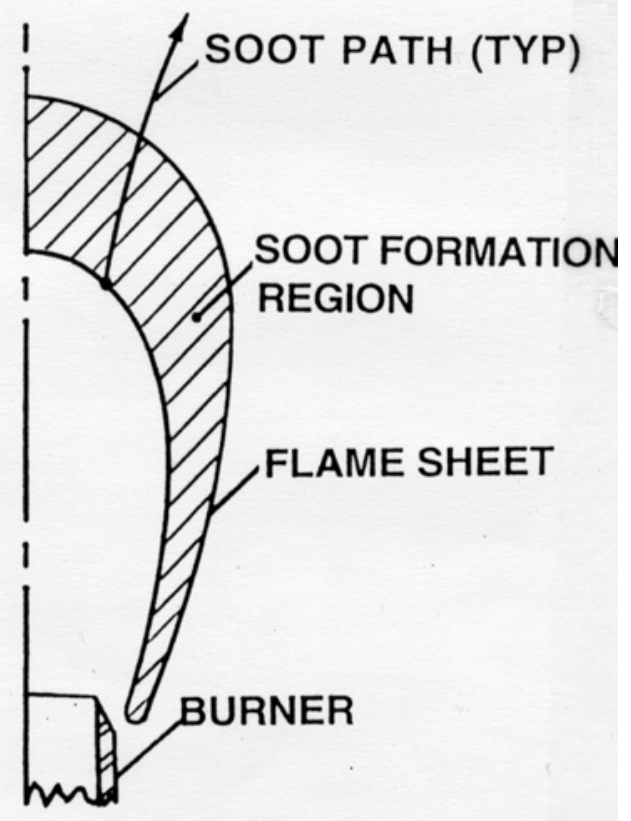

NONBUOYANT FLAME

Fig. 6 Flame shapes and typical pathlines in buoyant and nonbuoyant laminar jet diffusion flames. 


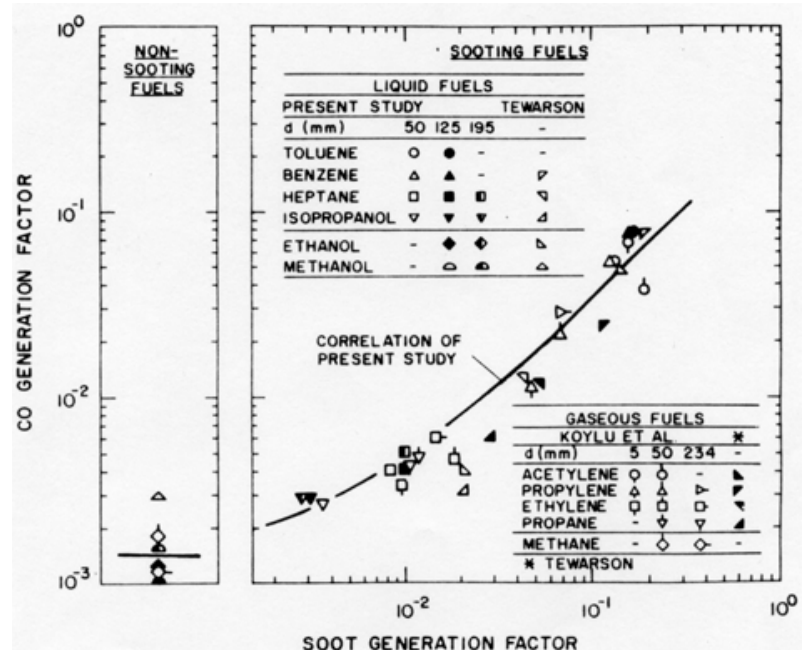

Fig. 7 Correlation between $\mathrm{CO}$ and soot generation efficiencies for buoyant turbulent alcohol, alkane, alkene and alkyne/air diffusion flames in the long residence time regime. From Köylü et al. ${ }^{71}$

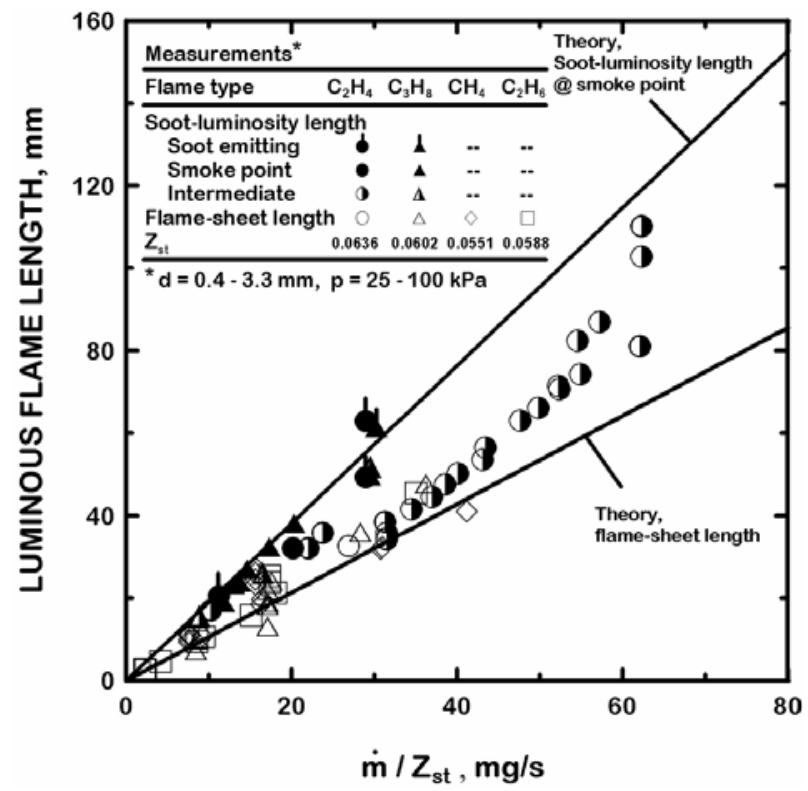

Fig. 8 Measured and predicted soot-luminosity and flame sheet lengths of nonbuoyant laminar round hydrocarbon/air flames as a function of fuel flow rate. Measurements of Lin et al. ${ }^{52}$, Aalburg et al. ${ }^{24}$ and Sunderland et al. ${ }^{49}$ Predictions based on Spalding. ${ }^{53}$

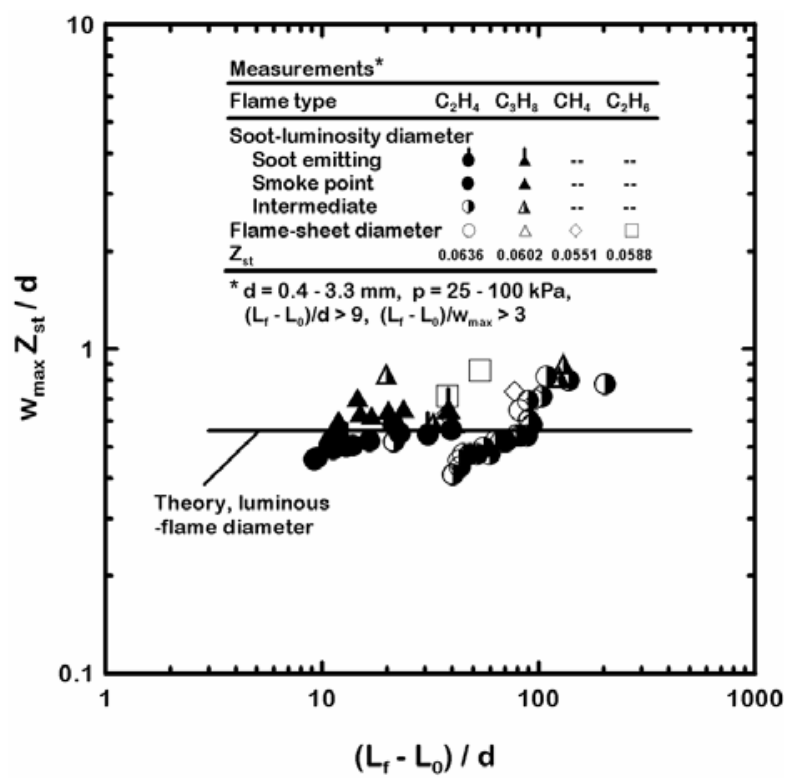

Fig. 9 Measured and predicted maximum sootluminosity and flame-sheet diameters of nonbuoyant laminar round hydrocarbon/air flames as a function of luminous flame length. Measurements of Urban et al. ${ }^{57}$, Lin et al. ${ }^{52}$, Aalburg et al. ${ }^{24}$ and Sunderland et al. ${ }^{49}$ Predictions based on Spalding. ${ }^{53}$ 

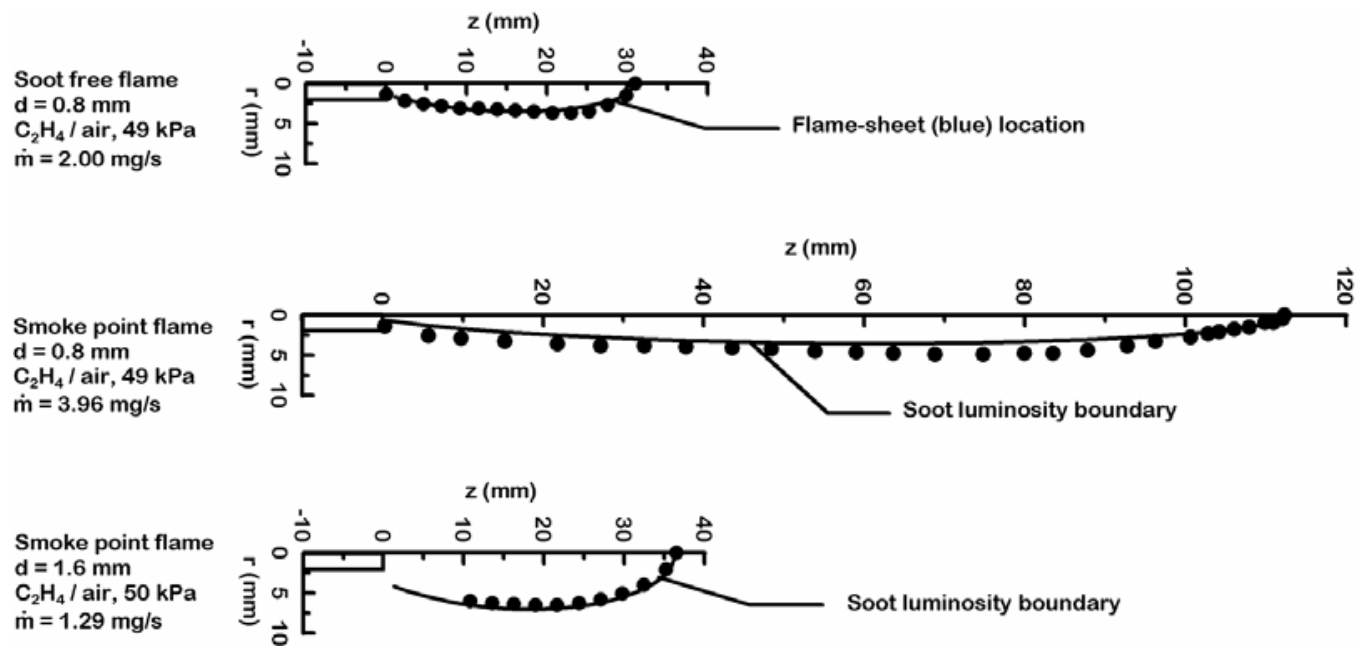

Fig. 10 Measured and predicted flame shapes during the flight experiments illustrating effects of burner fuel flow rate and burner diameter. Measurements of Aalburg et al. ${ }^{24}$ Predictions based on Spalding. ${ }^{53}$

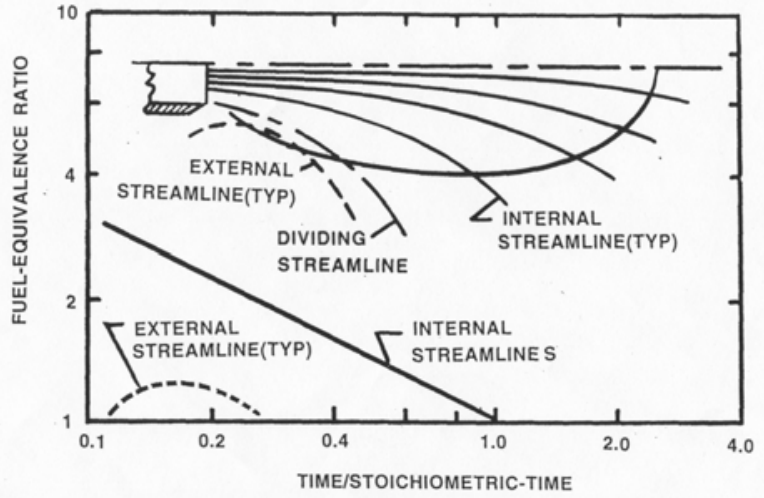

Fig. 11 Sketch of the streamline pattern and variation of fuel equivalence ratio as a function of time normalized by the stoichiometric time for nonbuoyant round laminar jet diffusion flames based on Spalding's ${ }^{53}$ analysis.

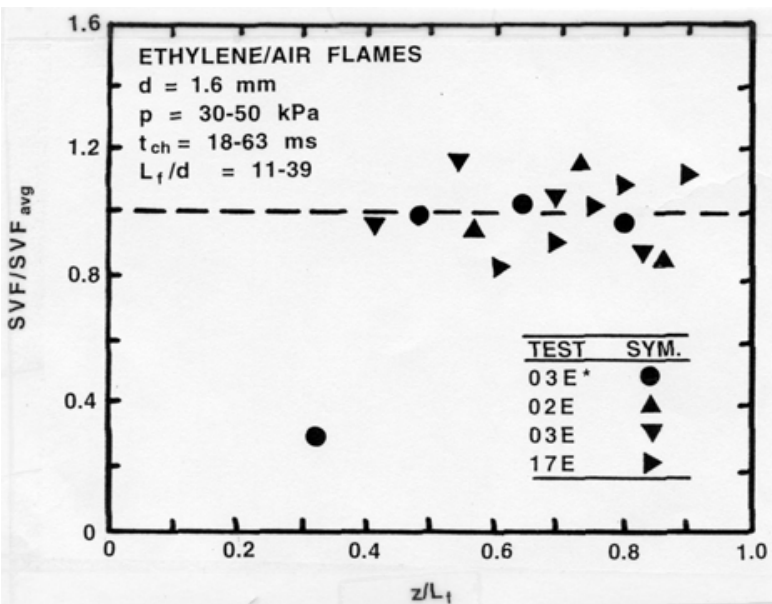

Fig. 13 Maximum soot volume fractions normalized by average maximum soot volume fractions for internal streamlines through closed-tip nonbuoyant laminar round ethylene-fueled flames burning in air. Measurements from Flight STS-94.

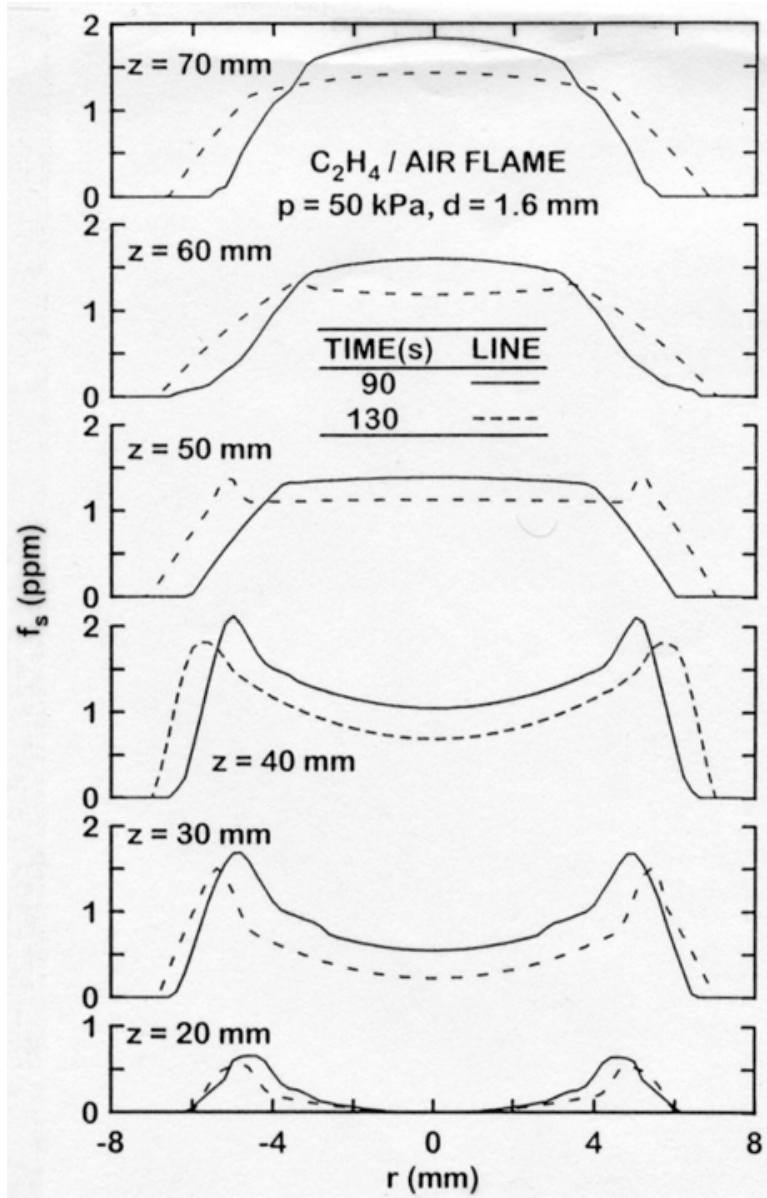

Fig. 12 Soot volume fraction distributions within a nonbuoyant laminar round ethylene/air closed-tip flame having a relatively short characteristic residence time (64 ms). Measurement from Urban et al. ${ }^{51}$

American Institute of Aeronautics and Astronautics 